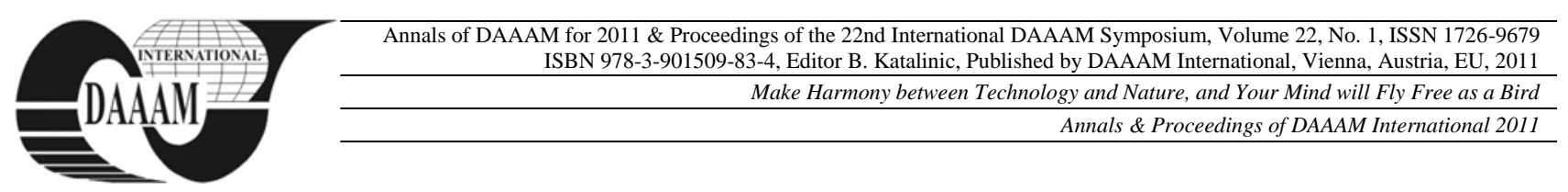

\title{
THERMAL EFFECTS ON METALS AT PLASMA CUTTING
}

\author{
STANEK, M[ichal]; MANAS, D[avid]; MANAS, M[iroslav]; OVSIK, M[artin]; SKROBAK, A[dam] \& \\ KRUMAL, M[artin]
}

\begin{abstract}
The submitted article describes the effects of a thermal separation of material on the properties of the surface layers. The separation of material is an integral part of a preparation of all final products. During cutting the surface layer of the separated material is effected, which then has an influence on the sequence of the following operations. The method of thermal separation of material was selected for the experiment described in the article a method of plasma cutting. The material selected for the method was a common steel $\check{C} S N$ 411 373, which is industrially produced and processed. The effect on the material was shown by measuring micro-hardness using the micro-hardness tester DM 2D.
\end{abstract}

Key words: micro hardness, plasma cutting, Vickers micro hardness

\section{INTRODUCTION}

As regards material separation methods, more sophisticated and effective methods are used today beside the classical ones. The new everyday development and changes of modern electronic technology and machine tool engineering brings new generations of many different products. Global development of these methods plays a vital role in the industrial process.

The cutting of material is usually the first operation that has to be done when producing some component. There are different types and methods of steel cutting. The most common methods of material splitting are cutting by water jet, laser, plasma and flame. In some cases, the heat caused by cutting influences the outer layers of the processed material.

Among two other common methods of cutting there are cutting by tools with defined geometry and abrasive processing - such as grinding or sanding. Some progressive methods could be also applied using physical, electrical and chemical processes as well as other sources of energy for removal of the material.

All these methods of material splitting force us to explore their impact to the qualities of cut material, especially to the layer that is in direct contact with the cutting tool. Learning about changes in structure and qualities of processed materials could assist in development of material separation and processing technologies.

\subsection{Testing of micro-hardness}

Development of hardness measurement methods for individual structural parts - measurement of micro-hardness was an important requirement for studying the structure of solids. Micro-hardness testing devices are inbuilt in metallographic microscopes or they are used as stand-alone devices.

Measurement of micro-hardness is done by pushing of the diamond body, shaped in Vickers or Knoop pyramid, into the surface of measured body by forces ranged from $1 \mathrm{~g}(0,009807$ $\mathrm{N})$ to $1000 \mathrm{~g}(9,807 \mathrm{~N})$. While common testing of (macro) hardness according to Vickers is done by means of load of $10 \mathrm{~N}$ to $1200 \mathrm{~N}$, the forces weaker than $10 \mathrm{~N}$ were used first in 1932, when such testing was done at the National Physical Laboratory in UK.

The accuracy of measurement is lower as the applied forces are weaker (smaller size of the dint). Moreover, as the load force weakens and enters the area of micro-hardness, the Vickers hardness is no more depending on the power of applied load (unlike in macro-hardness that is measured according to geometric similarity of individual dints).

\subsection{Micro-hardness according to Vickers}

Test of hardness according to Vickers is prescribed by European standard ČSN EN ISO 6507-1.

The penetrating body - made of diamond shaped as a regular tetragonal pyramid with the square base and with preset vertex angle $\left(136^{\circ}\right)$ between opposite walls - is pushed against the surface of testing body. Then, the diagonal size of the dint left after load removal is measured (Fig. 1).

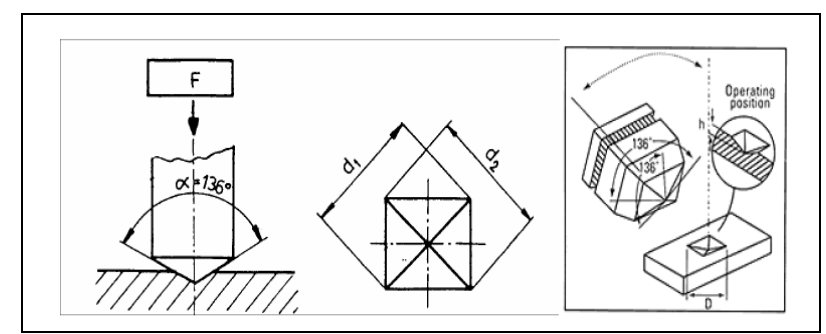

Fig. 1. The basic principle of hardness testing according to Vickers

$$
F=0,1891 \times\left(F / d^{2}\right)
$$

Where:

$\mathrm{F}$ - Testing load in $\mathrm{N}$

$\mathrm{d}$ - Arithmetic average of two diagonals $\mathrm{d} 1, \mathrm{~d} 2$ in $\mathrm{mm}$.

Vickers' hardness is then expressed as the ratio of the testing load applied to dint area in form of regular tetragonal pyramid with square base and the vertex angle equal to the angle of penetrating body $\left(136^{\circ}\right)$.

\section{EXPERIMENTAL PART}

There was one methods of material cutting selected in the experimental part. The method has a thermal impact to the outer layer. Steel ČSN 411373 was selected for testing of thermal influence in the cutting area. The testing sample was made by using the technology of cutting by laser. The sample preparation was done in companies specialized to these technologies of material cutting. 


\subsection{Micro-hardness testing according to Vickers}

A device used for micro-hardness testing is called microhardness tester.

Micro-hardness testing of structural components and phases is one of the most important tools used in metallographic industry. By means of micro-hardness testing, individual structural components could be identified relatively exactly, such as lower and upper bainit, lowly and highly carbonated martenzit etc.

The measurement is done by means of digital microhardness tester DM 2D from AFFRI. Measurement conditions are stated in the Tab. III above. The tester is able to measure the hardness according to Vickers as well as according to Knoop. An inbuilt 16bit monolithic high-power microprocessor equipped by photomechanical software was used. Its power can be fully adjusted according to the needs of micro-hardness testing in new century.

\begin{tabular}{|l|l|l|l|}
\hline \multirow{2}{*}{ Steel label } & \multicolumn{3}{|l|}{ Chemical composure (\%) } \\
\cline { 2 - 4 } & $\mathrm{C}$ & $\mathrm{P}$ & $\mathrm{S}$ \\
\hline ČSN & 0,17 & 0,045 & 0,045 \\
11373 & & & \\
\hline
\end{tabular}

Tab. 1. Chemical composure of steel 11373

\begin{tabular}{|l|l|}
\hline Load & $\begin{array}{l}200 \mathrm{~g} \\
(\mathrm{HV} \mathrm{0,2} \quad \mathrm{F}=1,961 \mathrm{~N})\end{array}$ \\
\hline Load time & $10 \mathrm{~s}$ \\
\hline
\end{tabular}

Tab. 2. Measurement conditions

\subsection{Sample preparation}

As the sample surface must have a metallic shine and the surface roughness must not excess $\mathrm{Ra} 0.2 \mu \mathrm{m}$, the sample preparation is very important step. In general, the sample could be fixed in a gripping or set into spaces and after grinding by soft grindstone, the sample has to be sanded by metallographic sand papers of different numbers so that the dint could be clearly seen.

\subsection{Plasma}

Plasmatic torch is a device for creating highly heated gaseous stream of ions and electrons (plasma). This jet stream is heated to very high temperature (over $30.000{ }^{\circ} \mathrm{C}$ ) by arc discharge and it streams in high speed from a narrow jet. The plasma ray can be deflected by means of magnetic field and accelerated by means of electric field. The splitting of testing material was done by means of $30.000{ }^{\circ} \mathrm{C}$.

Cutting by plasma creates the temperature about 30.000 ${ }^{\circ} \mathrm{C}$ in the cutting area and generator was used $100 \mathrm{~A}, \mathrm{Ar} / \mathrm{H}_{2}$. Environment temperature was $22{ }^{\circ} \mathrm{C}$. Despite the great difference between the temperatures in the cutting area and the surrounding environment, no significant changes on the surface layer around the incision line have occurred. This could be caused by very low content of carbon $(0,17 \%)$ and by slower speed of cooling that has not reached the critical speed and thus a non-equilibrium state (hardening) was not reached. On the opposite side, the lower speed of cooling occurred causing the creation of very fine pearlitic structure with hardness around 255 HV. Micro-hardness values could be seen in Fig. 2.

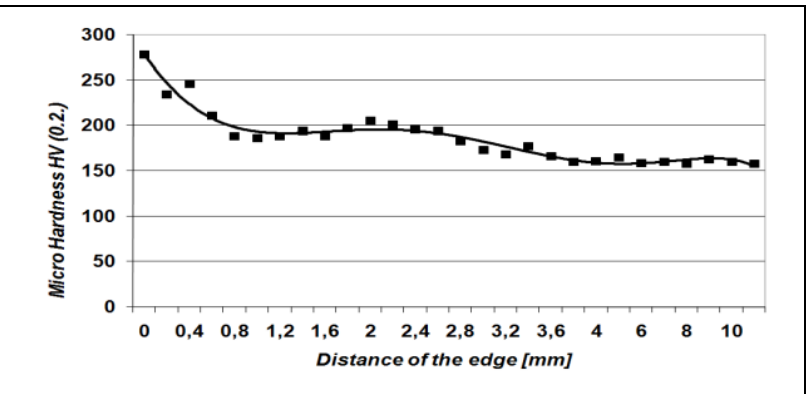

Fig. 2. Change of micro-hardness (cutting by plasma)

\section{CONCLUSION}

The submitted article deals with the impact of plasma cutting on the surface layer of material. The material used for

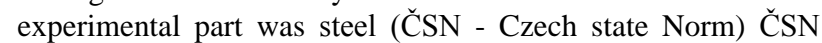
411373. The specimen thus made were ground (polished) and in this way prepared for the microhardness test. Microhardness was measured on the microhardness tester DM - 2D. The results of the measurement were put in the graph.

The results show that testing bodies cut by laser shown the hardness of $275 \mathrm{HV}$. Maximum thickness of the layer influenced by cutting was $1-1,5 \mathrm{~mm}$.

\section{ACKNOWLEDGEMENTS}

This article is financially supported by the internal grant of TBU in Zlín No. IGA/10/FT/11/D funded from the resources of specific university research and by the European Regional Development Fund under the project CEBIA-Tech No. CZ.1.05/2.1.00/03.0089.

\section{REFERENCES}

Oliver W.C.; G.M. Pharr.(1992) An improved technique for determining hardness and elastic modulus using load and displacement sensing indentation, J Mater Res 7 (6) pp. $1564-1583$.

Krumal, M.; Stanek, M.; Manas, M.; Manas, D.; Kyas, K. \& Cerny, J. (2010). Fluidity of Thermoplastic Elastomers, $D A A A M$, p. 1185, ISSN 1726-9679, ISBN 978-3-90150973-5, Zadar, Croatia

Manas, D.; Manas, M.; Stanek, M.; Sanda, S. \& Pata, V.(2011) Thermal effects on steel at different methods separation, Chemicke Listy 105 (17 SPEC. ISSUE), ISSN 0009-2770, pp. s713-s3716

Manas, D.; Stanek, M.; Manas, M.; Pata V. \& Javorik, J. (2009). Influence of Mechanical Properties on Wear of Heavily Stressed Rubber Parts, KGK - Kautschuk Gummi Kunststoffe, 62. Jahrgang, , ISSN 0948-3276, p.240-245

Manas, D.; Stanek, M. \& Manas, M. Workability and Wear of Rubber Parts, Chapter 54 in DAAAM International Scientific Book 2007, Published by DAAAM International, p.611- 626, Vienna, Austria, ISBN 3-901509-60-7, ISSN 1726-9687, DOI: 10.2507/daaam.scibook.2007.54

Stanek, M.; Manas, M.; Manas, D. \& Sanda, S. (2009). Influence of Surface Roughness on Fluidity of Thermoplastics Materials, Chemicke listy, Vol 103, ISSN 0009-2770, p.91-95

G.M. Pharr.(1998) Measurement of mechanical properties by ultra-low load indentation, Mater Sci Eng A253, pp. 151159 